\title{
Periventricular nodular heterotopia
}

INSERM

\section{Source}

INSERM. (1999). Orphanet: an online rare disease and orphan drug data base.

Periventricular nodular heterotopia. ORPHA:98892

Periventricular nodular heterotopia (PNH) is a brain malformation, due to abnormal neuronal migration, in which a subset of neurons fails to migrate into the developing cerebral cortex and remains as nodules that line the ventricular surface. Classical PNH is a rare $\mathrm{X}$-linked dominant disorder far more frequent in females who present normal intelligence to borderline intellectual deficit, epilepsy of variable severity and extra-central nervous system signs, especially cardiovascular defects or coagulopathy. The disorder is generally associated with prenatal lethality in males. 